\title{
Cytokinetic studies of crypts in convoluted human small-intestinal mucosa
}

\author{
NICHOLAS A. WRIGHT', DAVID R. APPLETON ${ }^{2}$, JANET MARKS ${ }^{3}$, AND \\ ALEXANDER J. WATSON ${ }^{1}$
}

From the Departments of ${ }^{1}$ Pathology, ${ }^{2}$ Medical Statistics, and ${ }^{3}$ Dermatology, University of Newcastle upon Tyne, UK

SUMMARY Forty-seven peroral biopsy specimens of duodenojejunal mucosa showing convolutions were obtained from patients with a variety of clinical disorders. These mucosal samples were divided into three groups according to the extent of the convolutions and the severity of the accompanying histopathological changes; the cytokinetic status of the crypts in the three groups was then analysed and compared. Those in which the mucosae were predominantly or totally convoluted (group 3 ) showed the most notable cytokinetic changes: crypts were hyperplastic and crypt cell production rate was markedly increased compared with the other two groups and with morphologically normal control mucosae.

In the case of one patient with mucosal changes of group 3 severity, additional studies were carried out using vincristine to produce metaphase arrest. The cell cycle time of 27 hours was greatly shortened compared with a control value of 45 hours.

We find that the presence of convolutions in small-intestinal mucosal biopsy specimens is accompanied by an increase in the rate of cell production from the crypts, which is presumably related directly or indirectly to the rate of loss of mature enterocytes from the surface of the mucosa. Furthermore, an increase in the proportion of convolutions may reflect an increase in the rates of cell production and cell loss.

In the group 3 convoluted mucosae the cytokinetic profile of the crypts resembled that of some of the flat avillous coeliac mucosae previously studied although the rates of cell production did not reach the levels attained by the most productive of the flat coeliac mucosae.

After the introduction of satisfactory methods for obtaining biopsy samples of small-intestinal mucosa by the peroral route it was soon observed that some jejunal mucosae presented a histological appearance intermediate between the normal villous state and the state of subtotal or total villous atrophy seen in untreated coeliac disease; this intermediate state was termed 'partial villous atrophy' (Doniach and Shiner, 1957). Subsequently it was found that a useful adjunct to histological examination is a preliminary examination of the biopsy specimen through a stereomicroscope (dissecting microscope) at low magnification under oblique illumination (Holmes et al., 1961). It was suggested that the term 'convoluted mucosa' should be used to describe the

${ }^{1}$ Present address: University Department of Pathology, Gibson Laboratories, Radcliffe Infirmary, Oxford.

Received for publication 8 November 1978 stereomicroscopic counterpart of partial villous atrophy because of a resemblance to the surface of the cerebral hemispheres.

Unlike the finding of a flat avillous duodenojejunal mucosa, with relatively small numbers of crypt vestibules opening on to the surface of mosaic plateaux, which is so highly characteristic of untreated coeliac disease as to be virtually diagnostic in appropriate clinical circumstances, the finding of a convoluted appearance is of uncertain significance as an isolated observation, and all other aspects of the case have to be taken into account (Watson and Wright, 1974). However, occasional patients with untreated coeliac disease do show variation in mucosal appearances in multiple biopsy specimens, and in these cases a convoluted appearance is not uncommon. Furthermore, it is well established that convolutions develop as an intermediate stage in the morphological recovery of a flat mucosa after gluten withdrawal, or in the regression of a recovered 
coeliac mucosa after re-exposure to gluten. In addition, convoluted duodenojejunal mucosae are quite commonly found in clinically mild or subclinical coeliac disease of dermatitis herpetiformis (Marks and Shuster, 1970) and in relatives of patients with coeliac disease (Robinson et al., 1972).

It is not germane to the purpose of this paper to review the evidence relating to the incidence of a convoluted form of duodenojejunal mucosa in apparently healthy subjects in different parts of the world (Baker, 1973) or to the frequency of its association with such intestinal disorders as tropical sprue (Baker et al., 1962; Swanson and Thomassen, 1965) or with various dermatological conditions (Marks and Shuster, 1970). In the literature we find that the term 'convoluted' has been used with different connotations by different workers and even by the same workers on different occasions; for example, it has been applied to mucosae with no more than single convolution (Shuster et al., 1967), or to those mucosae only in which convolutions were predominant (Salem and Truelove, 1965; Marks and Shuster, 1970), or more restrictively to those mucosae which were wholly convoluted (Scott et al., 1964). We have drawn a clear distinction between these categories of convoluted mucosae by allocating our biopsy specimens to one of three grades according to increasing severity of morphological abnormality based on well-defined stereomicroscopic and histopathological criteria; then by applying cytokinetic analytical techniques we have sought to establish whether there is a corresponding gradation of proliferative activity in the mucosal crypts. The findings have also been related to those which obtain in crypts of morphologically normal mucosae at one end of the spectrum and in the hyperplastic hyperproductive crypts of flat coeliac mucosae at the other. In one instance, viz, that of a patient with a completely convoluted duodenojejunal mucosa, additional cytokinetic data were obtained by comparing the findings in two mucosal biopsy specimens taken respectively before and at a suitable time interval after chemically induced stathmokinesis.
Material and methods

\section{BIOPSIES}

Forty-seven mucosal specimens were obtained by peroral biopsy of the duodenojejunal region. Most biopsies were taken in the middle of the day, which may minimise any diurnal variation of proliferative indices (Al-Dewachi et al., 1976). The specimens were spread on glass and examined under the stereomicroscope; they were then fixed in neutral buffered $10 \%$ formol-saline and post-fixed in formol-corrosive. The tissues were processed in the usual manner and embedded on edge in paraffin wax; serial sections were prepared at a thickness of $3 \mu \mathrm{m}$ and stained with Harris's haematoxylin.

\section{CLASSIFICATION OF MORPHOLOGICAL A P PEAR A NCES}

The biopsy specimens were subdivided into three groups $(1,2$, and 3$)$ on the basis of increasing severity of morphological abnormality upon stereomicroscopic and histological observation; the criteria are set out in Table 1 . Some specimens showed only one or two convolutions, distributed among ridges, leaves, and fingers in varying proportions, while others were completely or almost completely convoluted; the remainder fell between these two extremes. The presence of linear and curvilinear ridges did not contribute to the classification, since the aim of this study was to ascertain the significance of convolutions. The histological appearances ranged from normal to a state of undoubted abnormality, with crypt hyperplasia and incomplete villous atrophy approaching that seen in untreated coeliac disease. The biopsy specimen was placed in its appropriate group on the basis of whether stereomicroscopic or histological grading was worse, in the event that the two differed. The clinical diagnoses in each group are given in Table 2.

\section{MORPHOMETRIC VARIABLES}

Counting techniques were the same as those previously described (Wright et al., 1973a). In each

Table 1 Criteria for allocating convoluted mucosae to appropriate group according to increasing severity of morphological abnormality

\begin{tabular}{|c|c|c|c|}
\hline & Group 1 & Group 2 & Group 3 \\
\hline Stereomicroscopic & $\begin{array}{l}\text { One or at most a few convolutions } \\
\text { distributed among ridges, leaves, } \\
\text { and fingers in various proportions }\end{array}$ & $\begin{array}{l}\text { A range of appearances falling } \\
\text { between the extremes of groups } 1 \\
\text { and } 3\end{array}$ & Completely or predominantly convoluted \\
\hline Histological & No notable abnormality & $\begin{array}{l}\text { Evident shortening of villi; crypt } \\
\text { hyperplasia slight or inapparent; } \\
\text { mildly increased numbers of } \\
\text { inflammatory cells in lamina } \\
\text { propria; surface epithelium normal }\end{array}$ & $\begin{array}{l}\text { Pronounced villous shortening (less than } \\
\text { subtotal); obvious crypt hyperplasia; } \\
\text { readily apparent increase in density of } \\
\text { inflammatory cell infiltration of lamina } \\
\text { propria; abnormality of surface } \\
\text { epithelium (not mandatory) }\end{array}$ \\
\hline
\end{tabular}


Table 2 Clinical diagnosis related to morphological groups

\begin{tabular}{|c|c|c|c|c|c|}
\hline \multicolumn{2}{|l|}{ Group 1} & \multicolumn{2}{|l|}{ Group 2} & \multicolumn{2}{|l|}{ Group 3} \\
\hline Dermatitis herpetiformis (DH) & 5 & DH & 3 & DH & 7 \\
\hline Relatives of $\mathrm{DH}$ patients & 2 & Coeliac disease & 3 & Coeliac disease & 2 \\
\hline Anaemia (cause undetermined) & 1 & Eczema & 2 & Diarrhoea (colonic carcinoma) & 1 \\
\hline Coeliac disease (treated) & 1 & Failure to thrive & 2 & Giardiasis & 1 \\
\hline Diarrhoea (cause undetermined) & 1 & Crohn's disease (?) & 1 & Jejunitis (?cause) & 1 \\
\hline Eczema & 1 & Giardiasis & 1 & Malabsorption (Hodgkin's disease) & 1 \\
\hline Failure to thrive (child) & 1 & Iron-deficiency anaemia & 1 & Psoriasis & 1 \\
\hline Giardiasis & 1 & Malabsorption (?cause) & 1 & & \\
\hline Giardiasis (post-treatment) & 1 & Malnutrition & 1 & & \\
\hline \multirow[t]{3}{*}{ Psoriasis } & 1 & Postvagotomy diarrhoea & 1 & & \\
\hline & & Short stature & 1 & & \\
\hline & & Thymic alymphoplasia & 1 & & \\
\hline Totals & 15 & & 18 & & 14 \\
\hline
\end{tabular}

case at least 30 crypts were selected in which the base, middle, and mouth of the crypt were all in the plane of section. Care was taken to ensure that each crypt was analysed only once, and that the source of the sections was unknown to the observer. In each crypt the 'left-hand' column of cells was numbered, counting from the bottom upwards to the cryptvillus junction, and the cell positions of the mitotic nuclei were recorded. The number of cells present in a column (the crypt column length) and the number of crypt columns (the column count) were recorded. The latter was measured by turning the block and cutting sections tangentially to the bowel.

The data were analysed as previously described; results were expressed on a crypt whose length was the mean crypt column length for the group, and the mitotic index was then plotted against cell position in the crypt to give a mitotic index distribution curve for each group (Wright et al., 1973a).

\section{STATHMOKINETIC STUDY}

The patient studied was a man (RM) aged 25 with a clinical diagnosis of dermatitis herpetiformis and coeliac disease, who at the time of the present investigations showed no clinical or biochemical evidence of malabsorption. On day 1 a biopsy capsule was passed, and a mucosal biopsy of the duodenojejunal region was obtained in the normal way at 1330 hours. On day 2 , the capsule was passed to the same position as on the previous day, and at 1100 hours vincristine sulphate (Oncovin, Eli Lilly) was rapidly infused intravenously in a dose of 0.045 $\mathrm{mg} / \mathrm{kg}$ body weight. At 1330 hours the capsule was fired and a second mucosal biopsy was obtained. Care was taken to ensure that no appreciable movement of the capsule occurred during the stathmokinetic period following vincristine injection. The method of tissue processing, sectioning, and analysis was as before. Only prophases and metaphases were seen in the post-vincristine sample, indicating that the blocking effect of vincristine was still operative when this sample was taken.

In the pre-vincristine biopsy 204 crypts were suitable for analysis, and in the post-vincristine sample 210. The column count was estimated from transverse sections of 100 crypts from the pre-vincristine sample.

The correction factor of Tannock (1967) was measured, using a calibrated eyepiece graticule, in 139 transverse sections containing metaphases from the post-vincristine biopsy specimen.

\section{Results}

MORPHOLOGICAL GROUPS

Using the criteria of Table 1,15 specimens were assigned to group 1,18 to group 2 , and 14 to group 3 . There was good correlation between stereomicroscopic and histological appearances, although this was not perfect.

\section{MORPHOMETRIC VARIABLES}

These are given for the three groups in Table 3 where they are compared with results obtained in a series of 75 biopsies in which the stereomicroscopic and histological appearances were considered to be within normal limits (Wright et al., 1973a). There was enough material for the column count to be determined from 100 crypt cross sections in each of seven specimens from group 1, eight specimens from group 2 , and six specimens from group 3 . It is evident that there are increases in both crypt column length and column count with increasing severity of morphological changes. In all groups the crypt length and the column count were significantly greater than control values. Wimber and Lamerton (1963) reported that the product of the crypt length and column count gave a value for the crypt population which compared reasonably well with results obtained from counts of squashed, microdissected crypts. On this 
Table 3 Kinetic and morphometric measurements in convoluted groups compared with controls and adult coeliacs

\begin{tabular}{|c|c|c|c|c|c|c|c|c|}
\hline & $\begin{array}{l}\text { Crypt } \\
\text { column } \\
\text { length } \\
(\text { cells }) \ddagger\end{array}$ & $\begin{array}{l}\text { Column } \\
\text { count } \\
(\text { cells }) \ddagger\end{array}$ & $\begin{array}{l}\text { Crypt } \\
\text { population } \\
(\text { cells) }\end{array}$ & $\begin{array}{l}\text { Mitotic } \\
\text { index }(\%) \\
\text { (corrected) }\end{array}$ & $\begin{array}{l}\text { Growth } \\
\text { fraction }\end{array}$ & $\begin{array}{l}\text { Proliferating } \\
\text { population } \\
\text { (cells) }\end{array}$ & $\begin{array}{l}\text { Migration } \\
\text { rate }(\text { cell } \\
\text { positions/h) }\end{array}$ & $\begin{array}{l}\text { Crypt cell } \\
\text { production rate } \\
\text { (cells/crypt/h) }\end{array}$ \\
\hline $\begin{array}{l}\text { Controls (adult)* } \\
\text { Group } 1 \text { convoluted } \\
\text { Group } 2 \text { convoluted } \\
\text { Group } 3 \text { convoluted } \\
\text { Coeliac disease (adult) } \dagger\end{array}$ & $\begin{array}{l}31.9 \pm 0.1 \\
37.1 \pm 0.3 \\
39.0 \pm 0.3 \\
48.9 \pm 0.6\end{array}$ & $\begin{array}{l}24 \cdot 5 \pm 0.2 \\
25 \cdot 5 \pm 0.2 \\
27 \cdot 1 \pm 0.2 \\
30.8 \pm 0.3\end{array}$ & $\begin{array}{r}780 \\
950 \\
1060 \\
1510\end{array}$ & $\begin{array}{l}2 \cdot 1 \\
2 \cdot 4 \\
2 \cdot 6 \\
3 \cdot 8\end{array}$ & $\begin{array}{l}0.72 \\
0.74 \\
0.69 \\
0.77\end{array}$ & $\begin{array}{r}560 \\
700 \\
730 \\
1160\end{array}$ & $\begin{array}{l}0.7 \\
0.9 \\
1.0 \\
1.9\end{array}$ & $\begin{array}{l}17 \\
23 \\
28 \\
58\end{array}$ \\
\hline
\end{tabular}

*A series of 75 biopsies of morphologically normal mucosa (see Wright et al., 1973a).

+ A group of 13 biopsies of flat, avillous mucosa of adult coeliac disease (see Wright et al., 1973a).

\pm \pm SE.

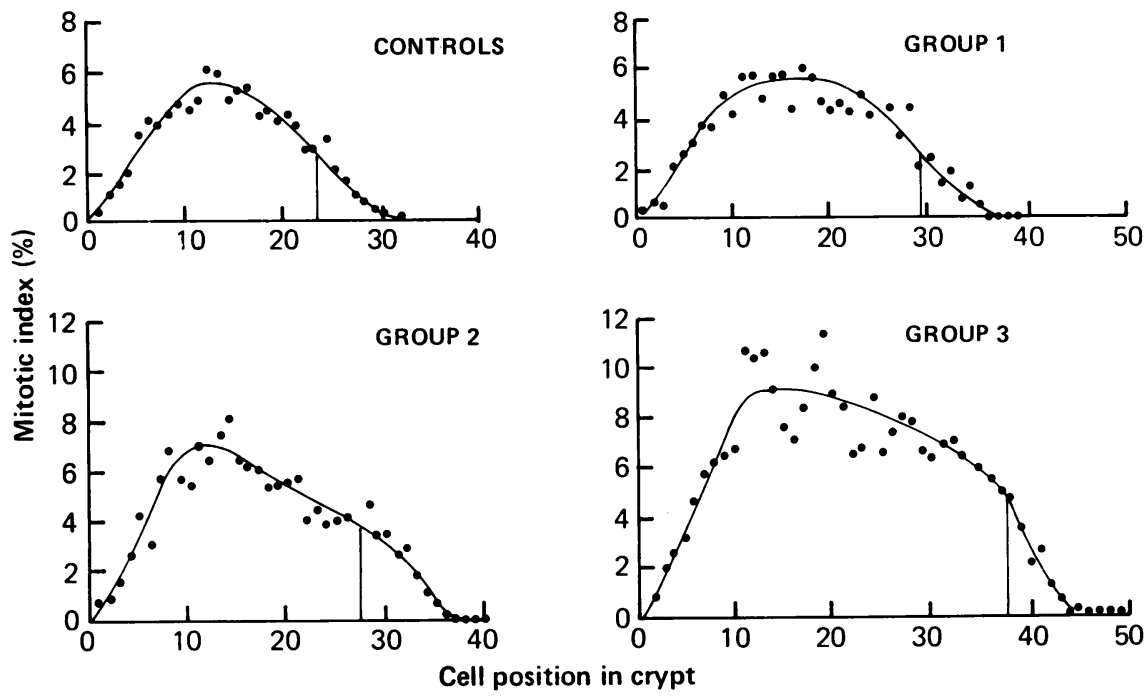

Fig. 1 Mitotic index distribution curves for convoluted groups 1,2, and 3 compared with a mitotic index curve for a group of 75 adult control patients with morphologically normal jejunal mucosae.

basis the results indicate increases in crypt population with increasing severity of morphological abnormality, and group 3 shows a doubling of crypt population compared with controls.

\section{MITOTIC INDICES}

The mitotic indices, with control values, are shown in Table 3. Although groups 1 and 2 show small increases compared with normal, only group 3 shows a significant increase in mitotic index.

\section{MITOTIC INDEX DISTRIBUTION CURVES}

Figure 1 shows the variation in mitotic index, plotted as a function of cell position in the crypt, for groups 1,2 , and 3 , and, for comparison, the mitotic index distribution curve for the group of adult controls is also shown. The curves are similar: low mitotic indices are seen in basal cell positions, and then the mitotic index rises to a maximum in the proliferative compartment of the crypt. In group 3 , the maximum index attained in the proliferative compartment exceeds $6 \%$ compared with a peak index of less than $4 \%$ in group 1 and controls. If all cells within the proliferative compartment are in the cell cycle, then the portion of the crypt delineated by the $50 \%$ peak point will be equivalent to the growth fraction (Cleaver, 1967). Even if we do not make this assumption the $50 \%$ peak point still gives a comparative measurement of the cut-off position in the crypt. or the point at which cells cease proliferating and enter the maturation compartment.

All groups show growth fractions which are close 

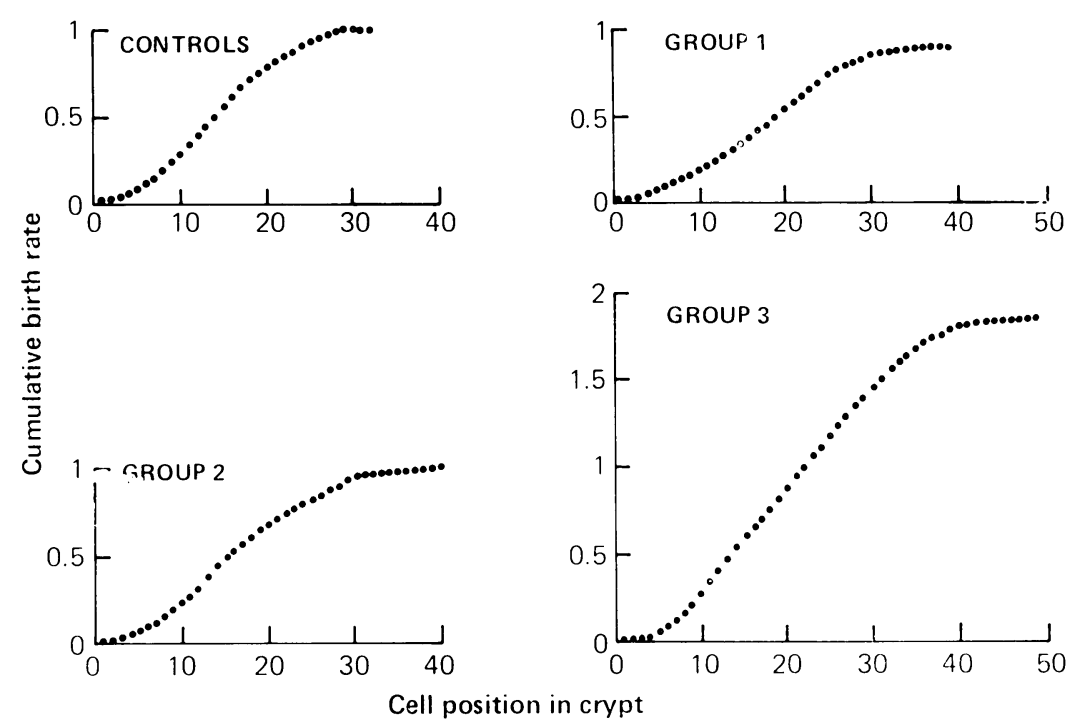

Fig. 2 Cumulative birth rate curves for convoluted groups 1, 2, and 3 compared with adult controls (units for cumulative birth rate are cells/cell position/h).

to control values. However, if we calculate the total number of proliferating cells per crypt from the growth fraction and the crypt population, then group 3 contains more than double the normal complement of proliferating cells (Table 3); much smaller increases are shown for groups 1 and 2 .

It can be seen from Table 3 that the total number of proliferating cells is close to that previously found in untreated adult coeliac disease (Wright et al., 1973a), in spite of the fact that the total crypt population is only half of that in coeliac disease.

\section{FLUX PARAMETERS}

The migration rate, or rate of migration of crypt cells in cell positions transvered per hour, and the crypt cell production rate (in cells/crypt/h) can be calculated from the mitotic index distribution data; the birth rate at each cell position was calculated as previously described (Wright et al., 1972), assuming that the duration of mitosis is one hour at each cell position (Wright et al., 1973b) in all cases. The efflux (in cells/cell/h) at the top of the crypt column (or at any cell position) is equal to the sum of the birth rates in all preceding cell positions; if crypt cells migrate because of mitotic activity in lower cell positions, the efflux at any cell position is also equal to the migration rate.

Cumulative birth rate curves for the three convoluted groups are shown in Figure 2. Group 3 has a larger maximum migration rate than groups 1 and 2 , attaining a rate of 1.9 cells per hour at the top of the crypt. The migration rates in groups 1 and 2 are close to the value found in controls (see Table 3).

From the cell production rate per crypt column and the column count (Table 3 ) we can estimate the crypt cell production rate. Table 3 shows that group 3 has a crypt cell production rate double that in the other two groups and more than three times that in control mucosae. However, values for group 3 are not as large as those found in the completely avillous flat mucosa, which is more characteristic of untreated coeliac disease (Wright et al., 1973a).

\section{STATHMOKINETIC STUDY}

Both biopsies from the patient studied showed a completely convoluted mucosal surface on stereomicroscopy, while histological examination showed group 3 type changes. Morphometric measurements for this patient are shown in Table 4. Crypt column length and column count are close to the means for group 3 (Table 3 ), and consequently the estimate of total crypt population is similar.

In the period of metaphase arrest, which was 2.5 hours, the mitotic index for the crypt rose (allowing for Tannock's correction factor, which was 0.69) from $3.2 \%$ to $9.6 \%$, a rise of $6.4 \%$ in 2.5 hours. Since metaphase arrest was complete, the rate of entry into mitosis was $2.6 \%$ of crypt cells per hour, assuming that vincristine took immediate effect.

An estimate, albeit an imprecise one, of the 
ble 4 Morphometric and kinetic measurements in a patient with convoluted mucosa of dermatitis herpetiformis compared th patients with morphologically normal and with flat avillous mucosae

\begin{tabular}{|c|c|c|c|c|c|c|c|c|c|c|c|}
\hline & $\begin{array}{l}\text { Crypt } \\
\text { column } \\
\text { length } \\
(\text { cells })\end{array}$ & $\begin{array}{l}\text { Column } \\
\text { count } \\
(\text { cells }) \ddagger\end{array}$ & $\begin{array}{l}\text { Crypt } \\
\text { population } \\
\text { (cells) }\end{array}$ & $\begin{array}{l}\text { Growth } \\
\text { fraction }\end{array}$ & $\begin{array}{l}\text { Proliferating } \\
\text { population } \\
\text { (cells) }\end{array}$ & $\begin{array}{l}\text { Migration } \\
\text { rate }(\text { cell } \\
\text { positions/h) }\end{array}$ & $\begin{array}{l}\text { Crypt cell } \\
\text { production } \\
\text { rate } \\
(\text { cells/crypt/h) }\end{array}$ & $\begin{array}{l}\text { Mitotic } \\
\text { duration } \\
(h)\end{array}$ & $\begin{array}{l}\text { Apparent } \\
\text { cell } \\
\text { cycle } \\
\text { time } \\
(h)\end{array}$ & $\begin{array}{l}\text { Cell } \\
\text { cycle } \\
\text { time } \\
(h)\end{array}$ & $\begin{array}{l}\text { Rate } \\
\text { of entry } \\
\text { into mitosis } \\
(\% \text { per hour })\end{array}$ \\
\hline $\begin{array}{l}\text { nvoluted mucosa } \\
\text { iult control* } \\
\text { at mucosa } †\end{array}$ & $\begin{array}{l}49.9 \pm 0.2 \\
31.9 \pm 0.2 \\
67.0 \pm 0.5\end{array}$ & $\begin{array}{l}29.3 \pm 0.7 \\
22.3 \pm 0.6 \\
30.4 \pm 0.5\end{array}$ & $\begin{array}{r}1460 \\
710 \\
2040\end{array}$ & $\begin{array}{l}0.72 \\
0.81 \\
0.60\end{array}$ & $\begin{array}{r}1050 \\
580 \\
1220\end{array}$ & $\begin{array}{l}1 \cdot 7 \\
0 \cdot 5 \\
1 \cdot 7\end{array}$ & $\begin{array}{l}50 \\
10 \\
50\end{array}$ & $\begin{array}{l}1 \cdot 2 \\
1 \cdot 1 \\
1 \cdot 3\end{array}$ & $\begin{array}{l}27 \\
45 \\
26\end{array}$ & $\begin{array}{c}19 \\
36 \\
16\end{array}$ & $\begin{array}{l}2 \cdot 6 \\
1 \cdot 5 \\
2 \cdot 7\end{array}$ \\
\hline
\end{tabular}

patient with morphologically normal mucosa studied by the two biopsy vincristine method (Wright et al., 1975).

patient with the flat, avillous mucosa of dermatitis herpetiformis studied with the two biopsy vincristine method (Wright et al., 1975).

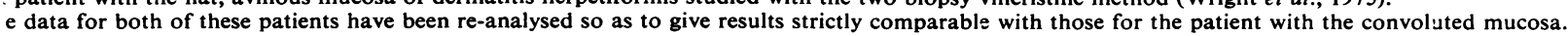

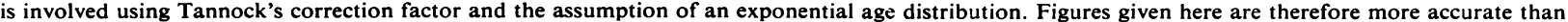
the reference cited.

-SE.

duration of mitosis $\left(t_{m}\right)$ can be calculated from the equation

$$
t_{m}=\frac{I_{m}(0) \cdot t}{\left(I_{m}(t)-I_{m}(0)\right)}
$$

where $I_{m}(0)$ is the mitotic index at time zero, $t$ is the duration of metaphase arrest ( 2.5 hours), and $I_{m}(t)$ is the mitotic index at time $t$. This gives a value of 1.2 hours, which is similar to control values (see Table 4).

The apparent cell cycle time, $T_{c}(a)$, which is the cell cycle time assuming that all crypt cells are proliferative, can be calculated, assuming an exponential age distribution, from

$$
T_{c(a)}=\frac{t \ln 2}{\left(I_{m}(t)-I_{m}(0)\right)}
$$

This gives a value of 27 hours, which is significantly different from control values (Table 4) and is close to values found in the flat mucosa of coeliac disease. To calculate the actual cell cycle time we must multiply $T_{c}(a)$ by the growth fraction. A value of 19 hours is obtained.

The mitotic index distribution curves before and after vincristine are shown in Figure 3. In the previncristine sample there is considerable variation in individual mitotic indices, but in the post-vincristine sample, because of the higher mitotic indices, variation is relatively less. Table 4 shows that the growth fraction and the proliferating population are similar to those found in group 3. Assuming that there is no movement of the arrested metaphases relative to the interphase crypt cell column, the rate of entry into mitosis at each cell position in the crypt can be calculated; this is shown in Figure 4. Data are available for cell positions 3 and above: low values are apparent at the low cell positions, but from cell positions 10 to 40 , values are about $0 \cdot 4$ cells $/$ cell/h.

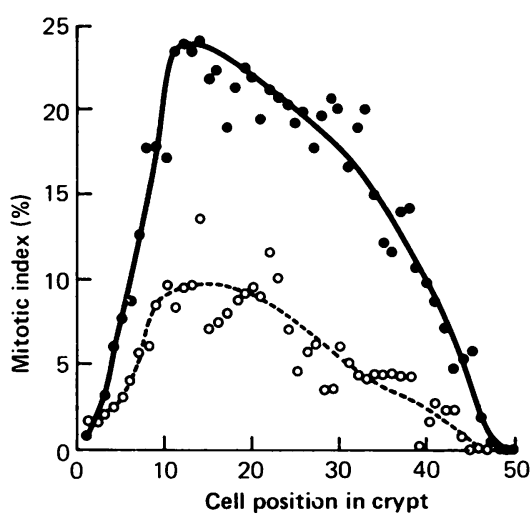

Fig. 3 Mitotic index distribution curves in the pre-vincristine and post-vincristine biopsy specimens for patient RM (group 3 convoluted mucosa):

$\bigcirc$ pre-vincristine; post-vincristine.

Finally, as cells decycle at the top of the crypt, mitotic rates decline.

From equation 1 the duration of mitosis can be calculated for each cell position, and hence the birth rate at each cell position can be calculated. The resulting cumulative birth rate curve is shown in Figure 5. The maximum migration rate attained is 1.7 cell positions per hour, and the crypt cell production rate is 50 cells/crypt/h.

\section{Discussion}

The results obtained here allow us to draw several conclusions about the physiological significance of the presence of convolutions in a jejunal biopsy, and also about the relationship between convoluted and flat jejunal mucosae.

The changes in group 3 are certainly most striking; this group showed an increase in total crypt cell 


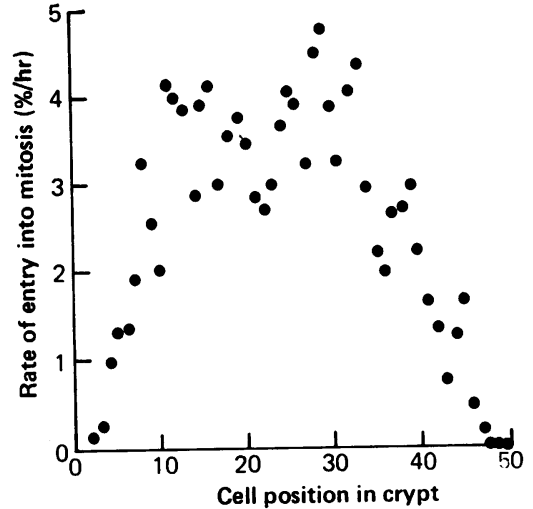

Fig. 4 Variation in rate of entry into mitosis $(\% / h)$ with cell position in crypt of patient $R M$.

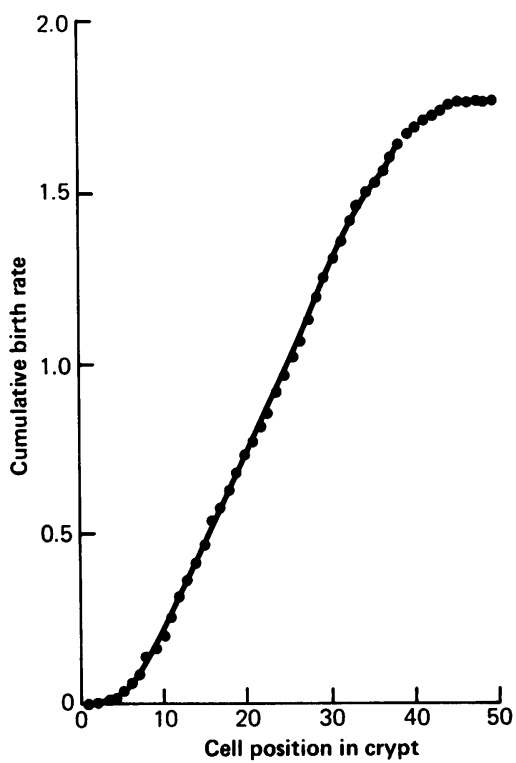

Fig. 5 Cumulative birth rate curve for patient $R M$ (units for cumulative birth rate are cells/cell position/h).

population, an increased number of proliferating crypt cells, and an elevated crypt cell production rate. Furthermore, analysis of a metaphase arrest study on a patient with the mucosal appearances of group 3 showed a significant decrease in apparent cell cycle time compared with control mucosae. It is concluded that mucosae with the appearances of group 3 , that is, predominantly or completely convoluted with pronounced villous shortening and with crypt hyperplasia, are in a hyperproductive state. However, this increase in crypt cell production is not as large as that found in flat mucosae (Wright et al., 1973a and b), although there may be some individual overlap in kinetic terms; for example, the migration rate and crypt cell production rate in the case for which we have these data were close to those found in a patient also with dermatitis herpetiformis but with a flat mucosa (Table 4).

An increase in crypt cell production rate presumably occurs in response to an increased rate of surface cell loss. Since in our group 3 the cell production rate is 58 cells/crypt/h, compared with 107 cells in flat mucosae (see Table 3), we may infer, by assuming that a state of balance is attained, that cell loss rate is not as large in convoluted mucosae as in flat mucosae. If we postulate that stable states of altered mucosal morphology in the small intestine are a reflection of the balance between cell production and cell loss, then our data are consistent with the hypothesis that a convoluted state represents the adjustment to a moderate increase in rate of cell loss, while a flat, avillous state is the result of a severe increase.

There appear to be at least three different mechanisms by which the intestinal crypt might increase its cell production rate to compensate for an increased rate of cell loss. Firstly, an increase in the crypt size, with an absolute increase in the population of proliferating cells, will lead to an increase in cell production rate although the growth fraction may be unaltered or even decreased; this response is evident in all of the convoluted groups. Secondly, an increase in the size of the proliferative compartment at the expense of the maturation compartment would increase the growth fraction and so lead to an increase in proliferation, but this response has not been observed in this study. Thirdly, a decrease in cell-cycle time would also increase the cell production rate; this has been shown to occur in the one patient with mucosal changes of group 3 severity so studied, but we have no information as to the occurrence of such a change in the other mucosae in this group or in those of groups 1 and 2. Consequently, we can only speculate as to the possible interrelationship of these compensatory responses. It seems likely that they are induced by some critical level or levels of cell-loss rate but they could be activated simultaneously or sequentially, and in the latter event they might or might not overlap. Observations of flat avillous mucosae in coeliac disease during morphological recovery after gluten withdrawal suggest that the convoluted state is intermediate between normality and total villous atrophy. Conversely, gluten challenge of a coeliac patient, whose flat mucosa has reverted to normality on a gluten-free diet, leads to a transient convoluted state during relapse to total villous atrophy. Our morphometric and cytokinetic findings are fully consistent with this inference 
although the same conclusion could not be established from our findings per se.

The morphological status, morphometric variables, and cell-kinetic characteristics of the specimen from the patient on whom stathmokinetic studies were performed place it in group 3 convoluted. The small differences in migration rate and crypt-cell production-rate from the means of that group may be explained in terms of the approximations to the mitotic durations that were used in the calculations.

In the analysis of the vincristine study we have made several assumptions: firstly, since only two biopsy specimens were available, that vincristine arrests metaphases immediately (Wright et al., 1973b); secondly, that the age distribution of cells is exponential (Cairnie et al., 1965; Appleton et al., 1977); and, thirdly, that the distribution of mitoses in the two biopsy specimens remained the same. Inspection of the mitotic index distribution curves before and after vincristine (Fig. 3) shows that the $50 \%$ peak point has moved from cell position 35 in the pre-vincristine sample to cell position 37 in the post-vincristine sample; therefore the distributions are reasonably similar.

We have demonstrated that there is a correlation between increasing prevalence of mucosal convolutions and a stepping-up of proliferative activity within the mucosal crypts, although the basis of this correlation remains a matter for speculation. It is probable that the formation of convolutions represents a morphological accommodation to a reduced population of surface cells (enterocytes), but this will be confirmed only when reliable methods have been developed for enumerating the surface cells on these complex structures. We suggest that our findings constitute additional evidence for the view that a convoluted duodenojejunal mucosa is not a definitive or end-stage pathological change but that it represents an intermediate stage between normality and a flat mucosa with total villous atrophy. In conclusion, we recommend that the term 'convoluted' as applied to small-intestinal mucosa be restricted, unless otherwise qualified, to connote degrees of abnormality which we have used to define our group 3 . The term 'partial villous atrophy' should be discarded (Watson and Wright, 1974), and, despite the deprecatory attitude of some authorities (Perera et al., 1975), we remain convinced that stereomicroscopy is a useful adjunct to histological assessment.

This work was supported by a grant from the North of England Cancer Research Campaign.

\section{References}

Al-Dewachi, H. S., Wright, N. A., Appleton, D. R., and
Watson, A. J. (1976). Studies on the mechanism of diurnal variation of proliferative indices in the small bowel mucosa of the rat. Cell and Tissue Kinetics, 9, 459-467.

Appleton, D. R., Wright, N. A., and Dyson, P. (1977). The age distribution of cells in stratified squamous epithelium. Journal of Theoretical Biology, 65, 769-779.

Baker, S. J. (1973). Geographical variations in the morphology of the small intestinal mucosa in apparently healthy individuals. Pathologia et Microbiologia, 39, 222-237.

Baker, S. J., Ignatius, M., Mathan, V. I., Vaish, S. K., and Chacko, C. C. (1962). Intestinal biopsy in tropical sprue. In Intestinal Biopsy (Ciba Foundation Study Group No. 14), edited by G. E. W. Wolstenhome and M. P. Cameron, pp. 84-101. Churchill, London.

Cairnie, A. B., Lamerton, L. F., and Steele, G. G. (1965). Cell proliferation studies in the intestinal epithelium of the rat. II. Theoretical aspects. Experimental Cell Research, 39, 539-553.

Cleaver, J. E. (1967). Thymidine Metabolism and Cell Kinetics. North Holland Publishing Company, Amsterdam.

Doniach, I., and Shiner, M. (1957). Duodenal and jejunal biopsies. II. Histology. Gastroenterology, 33, 71-86.

Holmes, R., Hourihane, D. O'B., and Booth, C. C. (1961). Dissecting-microscope appearances of jejunal biopsy specimens from patient with idiopathic steattorrhoea. Lancet, 1, 81-83.

Marks, J. M., and Shuster, S. (1970). Small-intestinal mucosal abnormalities in various skin diseases-fact or fancy? Gut, 11, 281-291.

Perera, D. R., Weinstein, W. M., and Rubin, C. E. (1975). Small intestinal biopsy. Human Pathology, 6, 157-217.

Robinson, D. C., Watson, A. J., Wyatt, E. H., Marks, J. M., and Roberts, D. F. (1972). Incidence of smallintestinal mucosal abnormalities and of clinical coeliac disease in the relatives of children with coeliac disease. Gut, 12, 789-793.

Salem, S. N., and Truelove, S. C. (1965). Small intestinal and gastric abnormalities in ulcerative colitis. British Medical Journal, 1, 827-831.

Scott, G. B., Williams, M. J., and Clark, C. G. (1964). Comparison of jejunal mucosa in post-gastrectomy states, idiopathic steatorrhoea, and controls using the dissecting microscope and conventional histological methods. Gut, 5, 553-562.

Shuster, S., Watson, A. J., and Marks, J. M. (1967). Small intestine in psoriasis. British Medical Journal, 3, 458-460.

Swanson, V. L., and Thomassen, R. W. (1965). Pathology of the jejunal mucosa in tropical sprue. American Journal of Pathology, 46, 511-551.

Tannock, I. F. (1967). A comparison of the relative efficiencies of various metaphase arrest agents. Experimental Cell Research, 47, 345-356.

Watson, A. J., and Wright, N. A. (1974). Morphology and cell kinetics of the jejunal mucosa in untreated patients. Clinics in Gastroenterology, 3, 11-31.

Wimber, D. R., and Lamerton, L. F. (1963). Cell population studies on the intestine of continuously irradiated rats. Radiation Research, 18, 137-146. 
Wright, N. A., Morley, A. R., and Appleton, D. R. (1972). Variation in the duration of mitosis in the crypts of Lieberkuhn of the rat: a cytokinetic study using vincristine. Cell and Tissue Kinetics, 5, 351-364.

Wright, N. A., Watson, A. J., Morley, A. R., Appleton, D. R., and Marks, J. (1973a). Cell kinetics in flat (avillous) mucosa of the human small intestine. Gut, 14, 701-710.

Wright, N. A., Watson, A. J., Morley, A. R., Appleton, D. R., Marks, J. M., and Douglas, A. (1973b). The cell cycle time in the flat (avillous) mucosa of the human small intestine. Gut, 14, 603-606.
Wright, N. A., Watson, A. J., Morley, A. R., Appleton, D. R., Marks, J. M., and Douglas, A. (1975). The measurement of cell production rates in the crypts of Lieberkuhn; an experimental and clinical study. Virchows Archiv A, Pathological Anatomy and Histology, 364, 311-323.

Requests for reprints to: Dr N. Wright, Nuffield Reader in Pathology, University Department of Pathology, Gibson Laboratories, Radcliffe Infirmary, Oxford OX2 6HE, UK. 